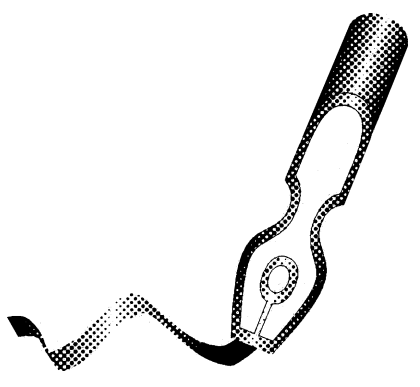

\title{
Ética en las publicaciones científicas
}

Al leer un artículo original en nuestra Revista uno puede criticar el método de estudio, estar de acuerdo con la hipótesis, considerar el tema interesante, etc. Pero es poco probable que uno cuestione la veracidad de lo comunicado ya que consideramos que la ciencia es equivalente a lo verdadero. Lamentablemente esto no es así.

El año 1992 se creó en Estados Unidos una agencia gubernamental denominada Office of Research Integrity, que podría traducirse como Oficina de Integridad en Investigación". Su objetivo es supervisar lo que ellos denominan como "mala conducta en investigación": Invención, falsificación o plagio. Como invención se entiende la fabricación de datos y su presentación como verdadera, falsificación corresponde a la manipulación u omisión de datos, y el plagio es la apropiación de resultados o sentencias de una tercera persona sin dar el crédito correspondiente.

Para la mayoría de nosotros resulta obvio que los resultados que se publican son los que se obtienen de acuerdo al material y método empleados, sin embargo, existen circunstancias donde hay estímulos perversos para que éstos se omitan. Por ejemplo, un estudio de la droga rofecoxib, denominado ensayo "Vigor", se diseñó para evaluar los efectos gastrointestinales de la droga en comparación con naproxeno, y los resultados fueron publicados en una prestigiosa revista ${ }^{2}$. En ese momento no fue comunicado por los autores que algunos pacientes del estudio sufrieron infarto agudo al miocardio, a pesar de conocer estos resultados cuando la publicación aún se encontraba en etapa de corrección 3 . Para el equipo editorial de una publicación científica resulta muy difícil poder sospechar la falsificación de información, por lo cual es muy importante la difusión de información y la educación al respecto de las nuevas generaciones.

La ética de las publicaciones científicas no sólo debiera incluir los conceptos de "mala conducta" previamente descritos. El año 1997 se creó una organización sin fines de lucro en el Reino Unido que agrupó editores de revistas científicas de dicho país, denominado Committee on Publication Ethics (COPE) ${ }^{4}$. Este grupo generó una recomendación que incluye los siguientes aspectos ${ }^{5}$ :

1. Diseño y aprobación por comité de ética. En nuestro país está vigente una ley que regula la investigación en seres humanos promulgada el año 2005, y que pone como requisito la aprobación del proyecto por un comité de ética. Por lo tanto, este punto no resulta un inconveniente. Tema aparte es la dificultad que tienen los investigadores para presentar sus proyectos a dichos comités y la aprobación de los mismos, lo cual podemos comentar en otra editorial.

2. Análisis de los datos. En este punto son relevantes la falsificación y fabricación de datos.

3. Autoría. Este punto es fuente de conflicto en todo el mundo. El International Committee of Medical Journal Editors, al cual nuestra publicación suscribe, define como autor a quien ha realizado una "contribución sustancial a la investigación"6. ¿Qué podemos entender como contribución sustancial? Este término resulta muy inespecífico y se ha optado por preguntar al autor que presenta el trabajo cuál ha sido el grado de colaboración 
de los coautores. El Comité Editorial desea enfatizar este punto. Como coautor se debe entender aquel colaborador que aportó en el diseño, ejecución y análisis final de los datos, y que es capaz de defender la publicación en su totalidad. También se puede considerar como coautor a la persona que prestó una colaboración técnica indispensable, por ejemplo en el desarrollo de una nueva técnica, y que también participa en la construcción de la publicación. En el caso de nuestra revista, cuando el artículo tenga más de 6 autores se le solicitará al autor principal que explique la razón del número de autores. Esto no constituye razón de rechazo del trabajo, sino en motivar un momento de reflexión en el seno del grupo de investigación.

4. Conflicto de interés. Es necesario que todos los autores declaren potenciales conflictos de interés, los cuales pueden ser de orden económico, personal, laboral u organizacional. Esto no constituye un motivo de rechazo ni tampoco invalida los resultados, sólo es una advertencia al lector.

5. Revisión por pares. Es la base de toda publicación científica. Este proceso también tiene sus pautas éticas que serán discutidas en una próxima editorial.

6. Publicaciones redundantes. Esto hace referencia a la publicación de varios trabajos con los mismos datos. Mención aparte merecen las traducciones de un artículo originalmente publicado en otro idioma, previa autorización de la revista original y con el advenimiento del editor.

7. Plagio. La apropiación de conocimientos de una tercera persona sin su consentimiento es una mala práctica y debe desalentarse.

8. Responsabilidad del editor. El rol del editor es clave en el funcionamiento de una publicación, y es un puesto de gran responsabilidad. Al recibir una publicación se debe evaluar si está dentro del ámbito de la revista, se debe considerar en su mérito sin influencias personales, se debe tener cuidado con publicaciones que rebatan conocimientos previos.

9. Relaciones con la prensa.

10. Avisaje. Se recomienda separar las labores del editor del financiamiento de la publicación. 11. Malas prácticas. Ya descrito.

Como se desprende del análisis de estas recomendaciones son muchos los factores que influyen en la ética de las publicaciones científicas, y en general, dependen de la confianza en que el investigador principal dice la verdad. Tratemos de ser un ejemplo para las nuevas generaciones ya que es nuestra mejor herramienta.

\section{BIBLIOGRAFÍA}

1. http://ori.dhhs.gov/.

2. Bombardier C, Laine L, Reicin A, Shapiro D, Burgos-Vargas R, Davis B, Day R, Ferraz MB, Hawkey CJ, Hochberg MC, Kvien TK, Schnitzer TJ; VIGOR Study Group. Comparison of upper gastrointestinal toxicity of rofecoxib and naproxen in patients with rheumatoid arthritis. VIGOR Study Group. N Eng/J Med 2000; 343(21): 1520-8, 2 p following 1528.

3. KRIMSKY H. When conflict-of-interest is a factor in scientific misconduct. Med Law 2007; 26: 447-63.

4. http://publicationethics.org/.

5. HUNTER JM. Ethics in publishing; are we practising to the highest possible standards? Br J Anaesth 2000; 85: 341-3.

6. http://www.icmje.org/. 